\title{
Ocean acidification reduces hardness and stiffness of the Portuguese oyster shell with impaired microstructure: a hierarchical analysis
}

\author{
Yuan Meng ${ }^{1}$, Zhenbin Guo ${ }^{2}$, Susan C. Fitzer ${ }^{3}$, Abhishek Upadhyay ${ }^{1}$, Vera B. S. Chan ${ }^{4,5}$, Chaoyi Li $^{1}$, Maggie Cusack ${ }^{6}$, \\ Haimin Yao $^{2}$, Kelvin W. K. Yeung ${ }^{7}$, and Vengatesen Thiyagarajan ${ }^{1,8}$ \\ ${ }^{1}$ The Swire Institute of Marine Sciences and School of Biological Sciences, The University of Hong Kong, \\ Pokfulam, Hong Kong SAR, China \\ ${ }^{2}$ Department of Mechanical Engineering, The Hong Kong Polytechnic University, Hung Hom, Kowloon, \\ Hong Kong SAR, China \\ ${ }^{3}$ Institute of Aquaculture, Faculty of Natural Sciences, University of Stirling, Pathfoot Building, Stirling, FK9 4LA, UK \\ ${ }^{4}$ Department of Biological Sciences, Clemson University, Clemson, SC, USA \\ ${ }^{5}$ Physiologie Fonctionnelle des Organismes Marins UMR 6539 LEMAR (CNRS/UBO/IRD/Ifremer), Ifremer, CS 10070, \\ 29280, Plouzané, France \\ ${ }^{6}$ Division of Biological \& Environmental Sciences, Faculty of Natural Sciences, University of Stirling, \\ Cottrell Building, Stirling, FK9 4LA, UK \\ ${ }^{7}$ Department of Orthopaedics and Traumatology, Queen Mary Hospital, The University of Hong Kong, \\ Pokfulam, Hong Kong SAR, China \\ ${ }^{8}$ State Key Laboratory for Marine Pollution, Hong Kong SAR, China \\ Correspondence: Vengatesen Thiyagarajan (rajan@hku.hk)
}

Received: 25 April 2018 - Discussion started: 29 May 2018

Revised: 9 August 2018 - Accepted: 21 September 2018 - Published: 16 November 2018

\begin{abstract}
The rapidly intensifying process of ocean acidification (OA) due to anthropogenic $\mathrm{CO}_{2}$ is not only depleting carbonate ions necessary for calcification but also causing acidosis and disrupting internal $\mathrm{pH}$ homeostasis in several marine organisms. These negative consequences of $\mathrm{OA}$ on marine calcifiers, i.e. oyster species, have been very well documented in recent studies; however, the consequences of reduced or impaired calcification on the end-product, shells or skeletons, still remain one of the major research gaps. Shells produced by marine organisms under OA are expected to show signs of dissolution, disorganized microstructure and reduced mechanical properties. To bridge this knowledge gap and to test the above hypothesis, we investigated the effect of OA on juvenile shells of the commercially important oyster species, Magallana angulata, at ecologically and climatically relevant OA levels (using pH 8.1, 7.8, 7.5, 7.2). In lower $\mathrm{pH}$ conditions, a drop of shell hardness and stiffness was revealed by nanoindentation tests, while an evident porous internal microstructure was detected by scanning electron microscopy. Crystallographic orientation, on the other hand,
\end{abstract}

showed no significant difference with decreasing $\mathrm{pH}$ using electron back-scattered diffraction (EBSD). These results indicate the porous internal microstructure may be the cause of the reduction in shell hardness and stiffness. The overall decrease of shell density observed from micro-computed tomography analysis indicates the porous internal microstructure may run through the shell, thus inevitably limiting the effectiveness of the shell's defensive function. This study shows the potential deterioration of oyster shells induced by $\mathrm{OA}$, especially in their early life stage. This knowledge is critical to estimate the survival and production of edible oysters in the future ocean.

\section{Introduction}

Edible oysters belonging to the genus Magallana have a complex life cycle, in which the free-swimming larvae attach onto a suitable hard substrate and then metamorphose into sessile juveniles within a few hours (Medaković et al., 1997; 
Salvi and Mariottini, 2017). The oyster larval shell is primarily made of aragonite, a denser and mechanically stronger form of calcium carbonate $\left(\mathrm{CaCO}_{3}\right)$, compared to calcite which is a stable but mechanically brittle polymorphous $\mathrm{CaCO}_{3}$ (Lawn and Wilshaw, 1993; Han et al., 1991). Upon metamorphosis, the fraction of calcite rapidly increases and becomes the main component in the juvenile and adult oyster shell (Medaković et al., 1997; Weiner and Addadi, 1997). The composition of the mineral and its organic matrix define a wide array of composites that relate to the mechanical strengths of the shell of each of these life stages (Lee et al., 2011). Early life stages of marine invertebrates, oysters included, are highly vulnerable to predators (Newell et al., 2007) and environmental stressors (Thomsen et al., 2015) when compared to the adult stages. Production of mechanically strong shells during larval and juvenile stages is essential to the post-larval phase because shell integrity and strength act as a protective barrier against shell-breaking and drilling predators.

Oceans currently absorb about a third of anthropogenic carbon dioxide $\left(\mathrm{CO}_{2}\right)$, which dissolves in seawater, forming carbonic acid, and increases the concentration of hydrogen ions, known as ocean acidification (OA). A study showed that the calcification rate of marine organisms, including oysters, is highly vulnerable to high carbon dioxide partial pressure $\left(p \mathrm{CO}_{2} ; \mu \mathrm{atm}\right)$ driven decreases in seawater $\mathrm{pH}$ (Feely et al., 2009; De Bodt et al., 2010). If the early life stages of edible oysters are vulnerable to near-future OA, then it could directly harm oyster survival and aquaculture production. Evidence of the negative effects of OA is, for example, the decline of spat production in oyster hatcheries on the west coast of the USA due to poorly calcified larval shells consequence of upwelled high $p \mathrm{CO}_{2}$ waters (Barton et al., 2012). Previous studies on calcifying organisms suggest that $\mathrm{OA}$ not only reduces calcification rates, but also increases dissolution of formed shells in very high $p \mathrm{CO}_{2}$ scenarios (Ries, 2011; Bednarsek et al., 2012). The decreased $\mathrm{pH}$ depletes carbonate ions necessary for $\mathrm{CaCO}_{3}$ mineralization, as well as weakens marine organisms physiologically by causing acidosis and impairing internal $\mathrm{pH}$ homeostasis needed for optimal calcification (Dupont and Portner, 2013). Recently, an increasing number of studies have captured the importance of the mechanical properties of calcareous shells, the end product of calcification, under OA scenarios (Dickinson et al., 2012; Ivanina et al., 2013; Li et al., 2014; Fitzer et al., 2015; Collard et al., 2016; Teniswood et al., 2016; Milano et al., 2016). For instance, it has been reported that the Pacific oyster, Magallana gigas (previously Crassostrea gigas), and the Eastern oyster, Crassostrea virginica, produced softer shells with reduced mechanical strength under OA conditions (Beniash et al., 2010; Dickinson et al., 2012). Despite these OA threats to oyster calcification process, studies are yet to demonstrate the structural organization of oyster shells under elevated $\mathrm{CO}_{2}$ conditions. Importantly, modulating effects of
OA on the inherent relationship between shell structural and mechanical features is yet to be studied in detail.

This study is designed specifically to fill this gap in knowledge using the ecologically and economically important edible oyster Magallana angulata (previously Crassostrea angulata) also as a model species. Here, the quantitative relationship between microstructural and mechanical properties was examined using the newly formed juvenile oyster shells. Specifically, the effect of OA on this relationship was tested using three levels of environmentally and climatically relevant high $\mathrm{CO}_{2}$ scenarios which induced decreased $\mathrm{pH}$. As the calcitic foliated layer is the major shell structure for mechanical support in oysters (Lee et al., 2008), we examined its structural and mechanical properties by using a variety of characterization and imaging techniques such as scanning electron microscopy (SEM), electron backscattered diffraction (EBSD) and nanoindentation tests. To further evaluate the overall shell integrity, we quantified shell density and shell density-volume ratio relationships using high-resolution micro-computed tomography scanning (micro-CT).

\section{Materials and methods}

\subsection{Experimental design}

Sexually matured adult oysters of the Portuguese oyster, $M a$ gallana angulata, were collected from the coastal area in $\mathrm{Fu}-$ jian, China $\left(26^{\circ} 05^{\prime} 53.36^{\prime \prime}\right.$ N $\left.119^{\circ} 47^{\prime} 45.81^{\prime \prime} \mathrm{W}\right)$, in the South China Sea on 29 July 2014. The adults were transported to the laboratory at the Swire Institute of Marine Science, University of Hong Kong. They were left to acclimatize in flowthrough tanks in natural seawater at ambient conditions (31 salinity, $29^{\circ} \mathrm{C}$ and $\mathrm{pH}_{(\mathrm{NBS})} 8.1$ ) for a week. They were fed with a mixed algae diet (Isochrysis galbana and Chaetoceros gracilis). Sperm and eggs were obtained from more than 10 males and 10 females using the "strip spawning" method (Dineshram et al., 2013), and cultured under ambient conditions. A period of $24 \mathrm{~h}$ post-fertilization, embryos developed into D-shaped veliger larvae.

Four environmentally and climatically relevant $\mathrm{pH}$ levels (the control: $\mathrm{pH} \mathrm{8.1;} \mathrm{the} \mathrm{low} \mathrm{treatments:} \mathrm{pH} 7.8,7.5$ and 7.2) were selected as proxies to investigate the effect of $\mathrm{CO}_{2}$ driven OA on oyster shells. According to IPCC projections, the average $\mathrm{pH}$ of oceans (currently $\mathrm{pH} 8.1$ ) is expected to drop to $\mathrm{pH} 7.8$ and 7.5 by the year 2100 and 2300, respectively (Feely et al., 2009). Lowest pH treatment was included in this study to understand the impact of extreme environmental conditions in the coastal habitats of $M$. angulata ( $\mathrm{pH}$ 7.2), which manifest naturally fluctuating $\mathrm{pH}$ levels up to -0.8 units due to river runoff and microbial respiration (Duarte et al., 2013; Thiyagarajan and Ko, 2012). Treatment levels of $\mathrm{pH}$ were maintained by bubbling filtered natural seawater with air enriched with $\mathrm{CO}_{2}$ at the required con- 


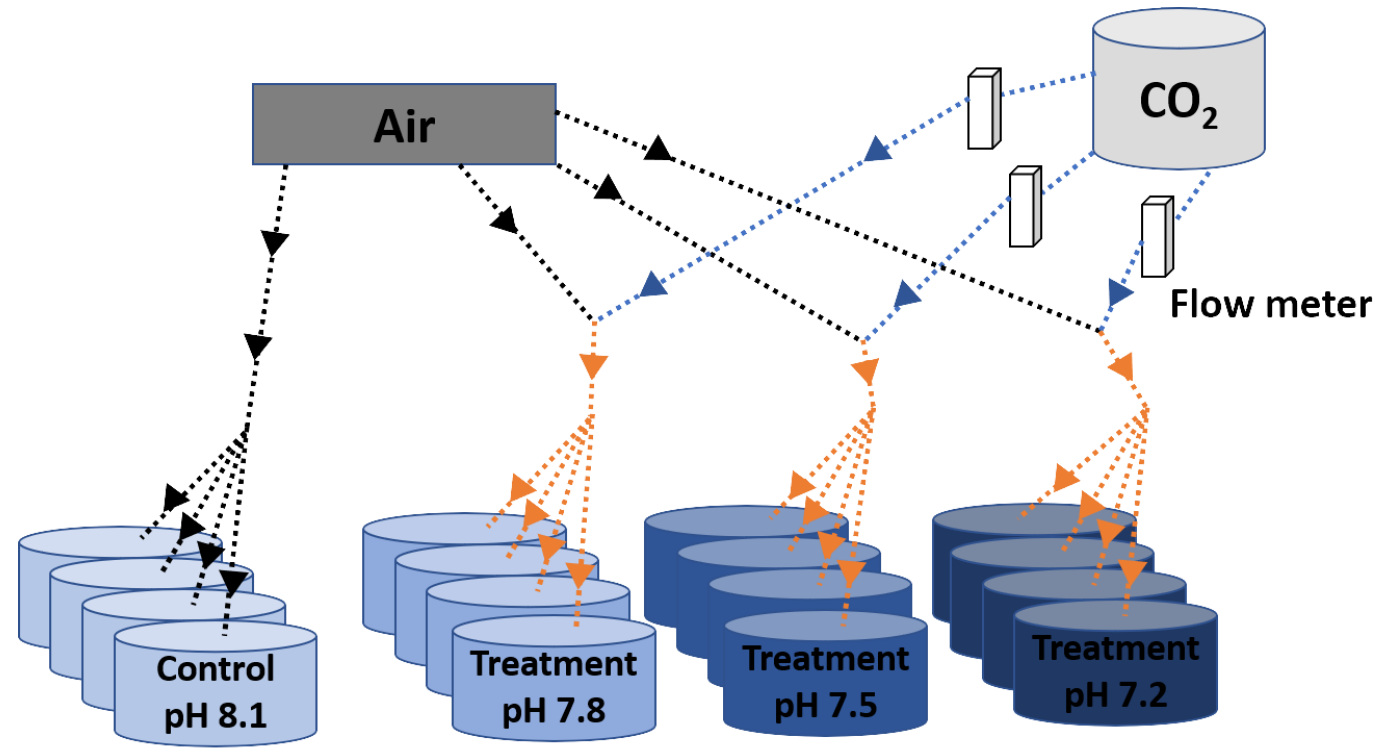

Figure 1. Scheme of the experimental system. Decreased $\mathrm{pH}$ conditions were obtained through bubbling $\mathrm{CO}_{2}$-enriched air with the appropriate $\mathrm{CO}_{2}$ concentration. Black and blue solid arrows indicate air and $\mathrm{CO}_{2}$ flow respectively and orange arrows indicate $\mathrm{CO}_{2}$-enriched air flow. The appropriate $\mathrm{CO}_{2}$ concentrations in the injected $\mathrm{CO}_{2}$-enriched air flow were controlled by using a dual variable area flow meter.

centrations using gas flow meters/controllers (Cole-Parmer, USA) (Fig. 1). Oyster larvae were raised from the D-shaped veliger stage to the juvenile stage under the four $\mathrm{pH}$ levels with four biologically independent replicates tanks for each treatment. D-shaped larvae $\left(10\right.$ larvae $\mathrm{mL}^{-1}, 50 \mathrm{~L}$ replicate tanks, $1 \mu \mathrm{m}$ FSW, 31 salinity, at $29^{\circ} \mathrm{C} \pm 2{ }^{\circ} \mathrm{C}$ ) were reared until the pediveliger stage following methods described by Dineshram et al. (2013). After about 2 to 3 weeks, larvae attained competency for attachment and metamorphosis. Larvae were transferred from each $50 \mathrm{~L}$ replicate tank to $1 \mathrm{~L}$ replicate tanks containing plastic substrates coated with 7-day-old natural biofilms. Attachment and metamorphosis took place within $24 \mathrm{~h}$. Attached oysters were reared in $1 \mathrm{~L}$ replicate tanks with the same $\mathrm{pH}$ level as before attachment for 35 days until collection. Larvae and juveniles were fed twice a day using a mixture of live I. galbana and C. gracilis $\left(5-10 \times 10^{6}\right.$ cells mL $\mathrm{mL}^{-1}, 1: 1$ ratio). Seawater $\mathrm{pH}$ (NBS scale) and temperature were measured using a Metter-Toledo (SG2) probe, and salinity was measured using a refractometer (ATAGO, S/MilloE; Japan). The probe was calibrated using NIST buffers ( $\mathrm{pH}=4.01,7.00$, and 9.21; Mettler Toledo, Gmbh Analytical CH8603 Schwerzenbach, Switzerland). In each culture, tanks levels of $\mathrm{pH}$, temperature and salinity were measured daily. Daily measurements were firstly averaged within and among days per each replicate tank. Samples of seawater $(50 \mathrm{~mL})$ from each culture tank were collected every 4 days and poisoned with $10 \mu \mathrm{L}$ of $250 \mathrm{mM}$ mercuric chloride for total alkalinity (TA) analysis using the Alkalinity Titrator (AC-A2, Apollo SciTech's Inc., US). The TA measurement was standardized with a certified seawater reference material (Batch 106, Andrew G. Dickson, Scripps In- stitution of Oceanography, USA). The carbonate system parameters, i.e. carbon dioxide partial pressure $\left(p \mathrm{CO}_{2} ; \mu \mathrm{atm}\right)$, carbonate ion concentration $\left(\mathrm{CO}_{3}^{2-} ; \mu \mathrm{mol} \mathrm{kg}{ }^{-1}\right)$, calcite and aragonite saturation state $\left(\Omega_{\mathrm{Ca}}, \Omega_{\mathrm{Ar}}\right)$, were calculated from $\mathrm{pH}$, salinity, temperature and TA measured from each replicated tank $(n=4)$, using the CO2SYS software program (Pierrot et al., 2006) with equilibrium constants $K_{1}, K_{2}$ and $K \mathrm{SO}_{4}$ (Mehrbach et al., 1973; Dickson and Millero, 1987). The treatment level (mean \pm SD; Table 1) was calculated using averages of the replicate culture tanks within each treatment $(n=4)$. On the 35th day post-metamorphosis, juveniles were collected and preserved in $75 \%$ ethanol for the following analyses (Chan et al., 2012).

\subsection{Shell microstructure analysis}

The sessile juvenile oyster permanently cements the left valve of its shell to the substratum, whereas its right valve provides protection from predators and the environment. In this study, only the right valve was used in the shell analysis. The surface topography of the intact shell was examined under variable pressure at $30 \mathrm{kV}$ using a scanning electron microscope (SEM; Hitachi S-3400N VP SEM, Hitachi, Japan). To examine sectional surface microstructures (MacDonald et al., 2010), shells were embedded in epoxy resin (EpoxyCure, Buehler) and sliced along the dorsal-ventral axis using a diamond trim saw blade. This allows for a more controlled comparison between the hinge region and the middle region of the shell. The hinge region (hereafter also referred to as "older shell") is the part of the shell that is deposited first by the juvenile oyster, whereas the middle re- 
Table 1. Seawater physico-chemical parameters in the experimental system.

\begin{tabular}{lrrrr}
\hline Treatments/parameter & Control & $\mathrm{pH} \mathrm{7.8}$ & $\mathrm{pH} \mathrm{7.5}$ & $\mathrm{pH} \mathrm{7.2}$ \\
\hline $\mathrm{pH}$ & $8.14 \pm 0.04$ & $7.88 \pm 0.02$ & $7.46 \pm 0.01$ & $7.23 \pm 0.01$ \\
Temperature $\left({ }^{\circ} \mathrm{C}\right)$ & $27.04 \pm 0.14$ & $27.02 \pm 0.08$ & $24.35 \pm 0.12$ & $27.50 \pm 0.08$ \\
Salinity $(\mathrm{psu})$ & $31 \pm 0.5$ & $31 \pm 0.5$ & $31 \pm 0.5$ & $31 \pm 0.5$ \\
$\mathrm{TA}\left(\mu\right.$ equiv kg $\left.^{-1}\right)$ & $2053.77 \pm 46.51$ & $2032.63 \pm 25.60$ & $2061.50 \pm 4.56$ & $2091.37 \pm 39.37$ \\
$p \mathrm{CO}_{2}(\mu \mathrm{atm})^{*}$ & $352.93 \pm 11.04$ & $861.37 \pm 130.34$ & $1997.23 \pm 124.42$ & $4091.73 \pm 447.85$ \\
$\mathrm{CO}_{3}^{2-}\left(\mu \mathrm{mol} \mathrm{kg}{ }^{-1}\right)^{*}$ & $175.66 \pm 24.96$ & $97.92 \pm 16.38$ & $48.82 \pm 6.07$ & $26.59 \pm 4.72$ \\
$\Omega_{\mathrm{Ca}}^{*}$ & $4.59 \pm 0.25$ & $2.43 \pm 0.41$ & $1.21 \pm 0.15$ & $0.66 \pm 0.12$ \\
$\Omega_{\mathrm{Ar}}^{*}$ & $3.01 \pm 0.18$ & $1.59 \pm 0.28$ & $0.79 \pm 0.10$ & $0.43 \pm 0.08$ \\
\hline
\end{tabular}

Data are mean \pm SD of the replicate culture tanks $(n=4)$ for the seawater physico-chemical parameters measured or calculated during the duration of the experiment: $\mathrm{pH}$ (National Bureau of Standards scale), temperature $\left({ }^{\circ} \mathrm{C}\right.$ ), salinity (psu), TA ( $\mu$ equiv $\mathrm{kg}^{-1}$ ), carbon dioxide partial pressure $\left(p \mathrm{CO}_{2} ; \mu \mathrm{atm}\right)$, carbonate ion concentration $\left(\mathrm{CO}_{3}^{2-} ; \mu \mathrm{mol} \mathrm{kg}{ }^{-1}\right)$, calcite saturation state $\left(\Omega_{\mathrm{Ca}}\right)$, and aragonite saturation state $\left(\Omega_{\mathrm{Ar}}\right)$. Values were first averaged within and among days per each of the replicate culture tanks. Afterwards, the treatment mean was computed. * Parameters were calculated using the CO2SYS software program (Pierrot et al., 2006) with equilibrium constants $K_{1}, K_{2}$ and $\mathrm{KSO}_{4}$ (Mehrbach et al., 1973; Dickson and Millero, 1987).

gion (hereafter also referred to as "younger shell") is the part of the shell that is deposited more recently. The edge region (Galtsoff, 1964), formed most recently, was not included in this study because it is too thin and fragile to handle. The sectioned surfaces were polished for 2 to $5 \mathrm{~min}$ using grit papers (P320, P800, P1200, P2500, and P4000) and etched for $20 \mathrm{~s}$ using $1 \%$ acetic acid, and then washed with distilled water and air-dried. The sectioned resin blocks were mounted on aluminium stubs using carbon adhesive tape with the polished side up. The area surrounding the specimen was painted with silver to reduce charge build-up, and the sectioned surfaces were sputter-coated with $50 \mathrm{~nm}$ thick gold-palladium alloy. The shell microstructure was examined under SEM with an accelerating voltage of $5 \mathrm{kV}$ using a LEO 1530 Gemini FSEM (Zeiss, Germany). The crosssectional porosity of foliated laminated structure was calculated using ImageJ software by standardizing and converting an SEM image to thresholding where the non-diffracted regions of SEM images were defined as pores. The pore area was then calculated by using the Image "Analyse Particles" feature due to the divergence in the size of pores. The pores area was sized with a confidence area greater than $0.001 \mu \mathrm{m}^{2}$. Three to four specimens from each treatment were randomly selected and examined $(n=3-4)$. All data were tested for normality of residuals, normality and homogeneity of variance before conducting analysis of variance (ANOVA). The Student-Newman-Keuls test was used to compare the means following one-way ANOVA.

\subsection{Shell crystallographic orientation analysis}

Shell crystallographic orientation was analysed by electron back-scattered diffraction (EBSD). Shells were prepared according to the above method, minus etching. The shell surfaces were ultra-polished for 4 min using cloths with 1 and $0.3 \mu \mathrm{m}$ Alpha alumina powders and for 2 min using colloidal silica. In order to investigate both larva aragonite and ju- venile calcite composition, an area throughout the sectional surface of the older hinge regions was selected. The EBSD analyses were carried out under low vacuum mode $(\sim 50 \mathrm{~Pa})$ with a beam voltage of $20 \mathrm{kV}$ using an FEI Quanta $200 \mathrm{~F}$ with the stage tilted at $70^{\circ}$ to examine back-scattered Kikuchi patterns (Perez-Huerta and Cusack, 2009). Diffraction intensity, phase and crystallographic orientation maps were produced using the OIM Analysis 6.2 software. Data was partitioned through two clean-up procedures to display grains with a confidence index greater than 0.1. Pole figures were used to illustrate the spread of crystallographic orientation (Perez-Huerta and Cusack, 2009). The colours in the crystallographic orientation maps and pole figures were used to quantify the crystallographic orientation. Two randomly selected specimens were examined per treatment.

\subsection{Shell mechanical properties analysis}

After SEM and EBSD analysis, the resin blocks were repolished for 5 min using grit papers (P2500 and P4000) and for another 5 min using cloth with colloidal silica to remove the gold-palladium coating and etched shell surface. The mechanical properties of the polished longitudinal cross sections were determined by measuring the hardness $(H)$ and stiffness $(E)$ using load and displacement sensing nanoindentation tests (Perez-Huerta et al., 2007). Hardness and stiffness of foliated layers were measured in the older hinge and younger middle regions of the specimens used in the SEM analysis. The nanoindentation tests were carried out from the interior to the exterior shell in these regions at ambient temperature with a Hysitron TriboIndenter TI 900 (TI 900, Hysitron, MN, USA) equipped with a Berkovich indenter (with a half-angle of $63.5^{\circ}$ ). Indentations were made in each specimen using a 6-11 indent-per-row pattern and a maximum load of $2000 \mu \mathrm{N}$ with valid contact depth of 16 to $184 \mathrm{~nm}$. The hardness and stiffness from each indentation were obtained from the loading-unloading curve us- 


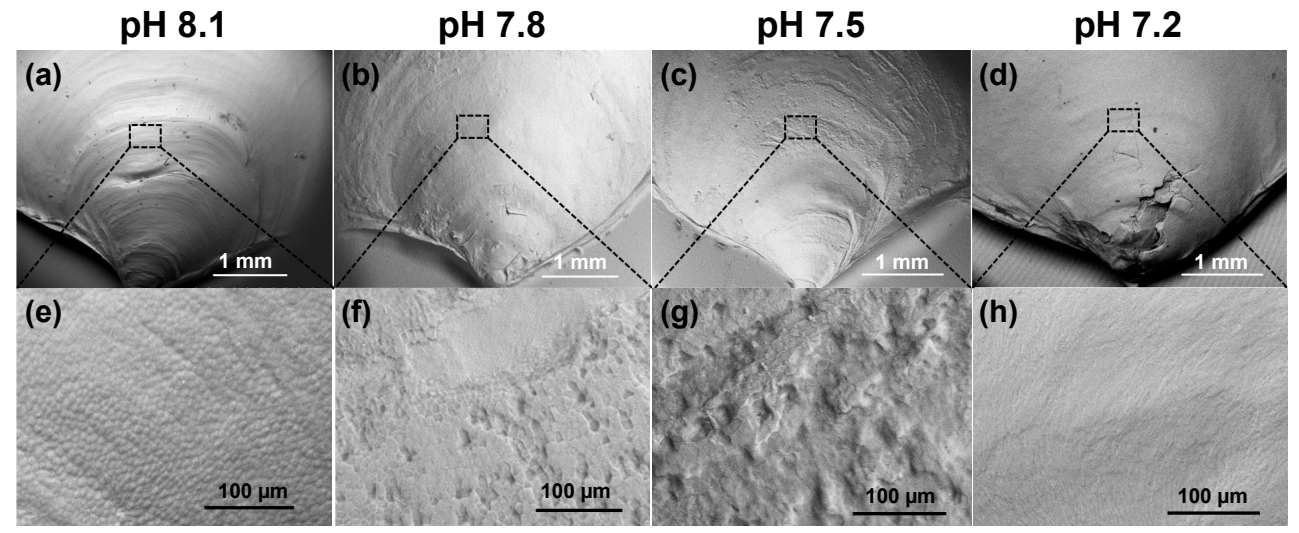

Figure 2. Scanning electron micrographs of 35-day-old juvenile Magallana angulata shells cultured at ambient or control $\mathrm{pH} 8.1$ (a, e), treatment pH $7.8(\mathbf{b}, \mathbf{f}), \mathrm{pH} 7.5(\mathbf{c}, \mathbf{g})$ and $\mathrm{pH} 7.2(\mathbf{d}, \mathbf{h})$ were compared. Panels (a-d) show the low magnification tomography of the juvenile shells. Panels (e-h) show the enlarged view of the crystallite units (top view). (e) The prism units were arranged in compact prismatic structures at $\mathrm{pH}$ 8.1. (f) Prismatic arrangement was partially lost at $\mathrm{pH}$ 7.8. (g) A rough surface was observed, demonstrating a much lower level of organization at $\mathrm{pH}$ 7.5. (h) A smooth surface was observed with no prismatic arrangement due to dissolution by environmental seawater.

ing the Oliver-Pharr model (Doerner and Nix, 1986; Oliver and Pharr, 1992). Five to six specimens of each treatment were randomly selected for nanoindentation tests (one to two specimens per replicate tanks). Measurements per replicate tanks were calculated by firstly averaging the values among indentations per specimen, and then among specimens per replicates. Afterwards, the effect of decreased $\mathrm{pH}$ on the hardness and stiffness of juvenile oyster shells was compared by three to four replicate measurements $(n=3-4)$. All data were tested for normality of residuals, normality, and homogeneity of variance before conducting ANOVA. The Student-Newman-Keuls test was used to compare the means following one-way ANOVA.

\subsection{Shell density analysis}

The three-dimensional shell density maps, the overall shell density and the density-volume ratio relationships were obtained using a high-resolution micro-CT scanning system (SkyScan 1076, Skyscan, Kontich, Belgium) with a spatial resolution of $9 \mu \mathrm{m}$. Individual shells were placed in a small plastic container held securely in the chamber of the microCT scanner. Shell densities and the corresponding volume ratios of partial density were calculated by relative comparison using standardized phantoms used for bone density measurement in the analytical software CT-Analyser v 1.14.4.1 (SkyScan) (Celenk and Celenk, 2012). The threedimensional digital data were converted from $\sim 1000$ twodimensional layers using reconstruction software CT-Volume v 2.2.1.0 (SkyScan). Three randomly selected specimens were used per treatment $(n=3)$. The volume ratio with partial density ranges of 0 to $0.5,0.5$ to 1 and $>1.5 \mathrm{~g} \mathrm{~cm}^{-3}$, and density of the treatment groups were compared with the controls by following one-way ANOVA. For the datasets that did not meet the requirement of variance homogeneity, i.e. the volume ratio with a partial density range of 1 to $1.5 \mathrm{~g} \mathrm{~cm}^{-3}$, Kruskal-Wallis tests were used to compare the effect of $\mathrm{pH}$ on these shell properties. For all other datasets, the StudentNewman-Keuls test was used to compare the means by following one-way ANOVA. Otherwise, Dunn's test was used after the Kruskal-Wallis test. Linear regressions (volume ratio $(\%)=b \times$ density $\left.\left(\mathrm{g} \mathrm{cm}^{-3}\right)+a\right)$ were utilized to determine the relationships between shell density and the corresponding volume ratio; $a$ is the $y$ intercept and $b$ is the scaling exponent of consumption. To compare slopes of the resulting linear models, analysis of covariance (ANCOVA) was performed by using $\log _{10}$ transformed volume ratio as the dependent variable, $\mathrm{pH}$ levels as the independent variable, and shell density range as covariates. All data met the homogeneity of variance and normality assumptions of parametric tests. ANCOVA were implemented in R 3.3.2 using the statistical package Linear and Nonlinear Mixed Effects Models (R Core Team, 2013).

\section{Results}

\subsection{Shell surface and internal microstructure}

As shown by the SEM, decreased $\mathrm{pH}$ altered both shell topography (Fig. 2) and internal microstructure (Fig. 3). Mineral dissolution was prominent on the outer surface layers of shells under decreased $\mathrm{pH}$. The shells of juveniles raised at pH 7.8 (Fig. 2b, f) and pH 7.5 (Fig. 2c, g) showed signs of dissolution or physical damage when compared to the controls ( $\mathrm{pH}$ 8.1) (Fig. 2a, e). At the lowest $\mathrm{pH}$ of 7.2 with undersaturated calcite conditions, the outer prismatic layer was completely absent at the older hinge and younger mid- 

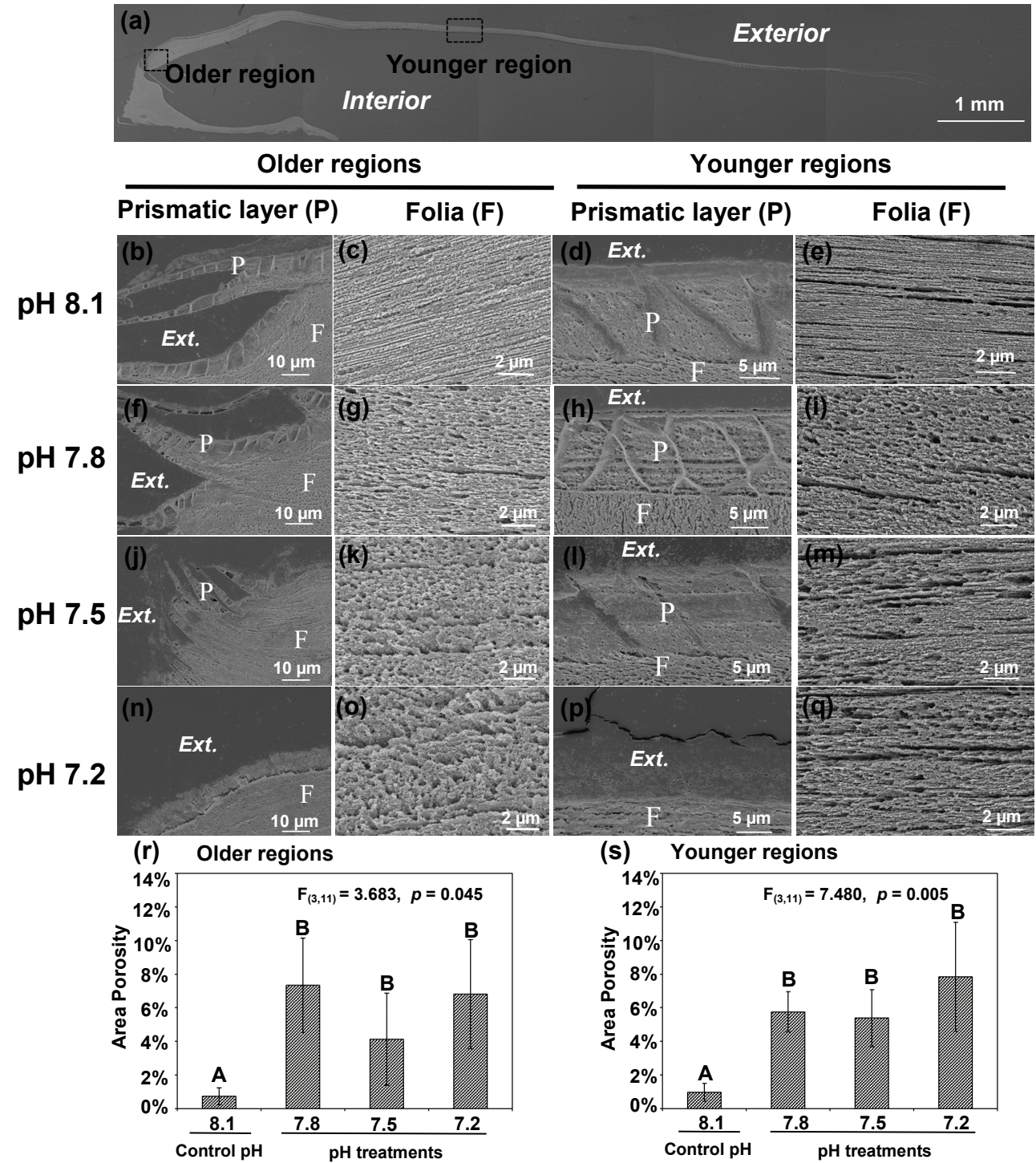

Figure 3. Microstructures were observed in the cross-sectional shell surfaces of 35-day-old juvenile Magallana angulata. Scanning electron micrographs were taken near the older hinge region $(\mathbf{b}, \mathbf{c}, \mathbf{f}, \mathbf{g}, \mathbf{j}, \mathbf{k}, \mathbf{n}, \mathbf{o})$ and the younger middle region $(\mathbf{d}, \mathbf{e}, \mathbf{h}, \mathbf{i}, \mathbf{l}, \mathbf{m}, \mathbf{p}$ and $\mathbf{q})$. Panel (a) shows the scanning electron micrograph of the full shell cross-sectional surface. Second row: the prismatic layer (b, d) and tightly packed foliated structure $(\mathbf{c}, \mathbf{e})$ at $\mathrm{pH}$ 8.1. Third row: the prismatic layer $(\mathbf{f}, \mathbf{h})$ and the foliated structure with more and bigger pores $(\mathbf{g}$, i) at $\mathrm{pH} 7.8$ compared with at $\mathrm{pH}$ 8.1. Fourth row: the incomplete prismatic layer $(\mathbf{j}, \mathbf{l})$ and more porous foliated structure $(\mathbf{k}, \mathbf{m})$ at $\mathrm{pH} 7.5 \mathrm{compared}$ with at $\mathrm{pH}$ 8.1. Fifth row: the prismatic layer was not detectable (n, p) with porous foliated structure (o, q) at $\mathrm{pH} 7.2$. The porosity of foliated layers at the older $(\mathbf{r})$ and younger regions (s) of the shell reared under control and low $\mathrm{pH}$ treatments. The mean values are presented in the bar chart (mean $\pm \mathrm{SD}, n=3-4)$. Annotations: $\mathrm{P}$ is the prismatic layer; $\mathrm{F}$ is the foliated layer.

dle regions of the shell (Fig. 2d, h). Though the overall calcitic foliated laminas' alignment was retained, those in the shells of controls ( $\mathrm{pH} 8.1)$ were compactly arranged and well-ordered with minimal gaps between layers (Fig. 3c, e). In contrast, the foliated layers in shells under all three decreased $\mathrm{pH}$ treatments presented a more porous alignment in that the foliated laminas were less tightly packed and irregularly arranged (Fig. 3g, i, k, m, o and q). The area porosity of foliated layers increased significantly with decreasing $\mathrm{pH}$ levels, regardless of older and younger shell (older region: $F_{(3,11)}=3.683, p=0.045$; younger region: $F_{(3,11)}=7.480$, $p=0.005$; Fig. 3r, s).

\subsection{Crystallographic orientation}

Electron back-scattered diffraction (EBSD) intensity mapping analysis showed diffraction patterns for both calcite and aragonite crystals of older hinge regions in the juvenile shells (Fig. 4). The crystallographic orientation maps 
(a)

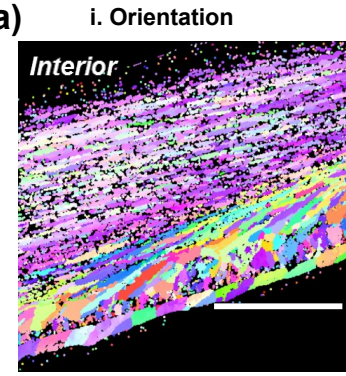

(b)

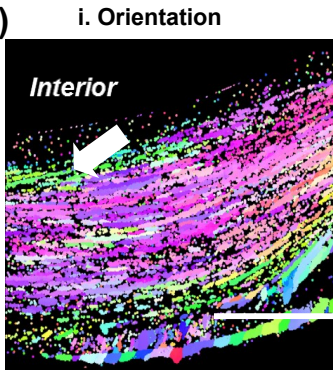

(c)

i. Orientation

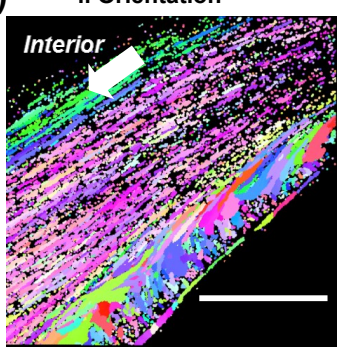

(d)

i. Orientation

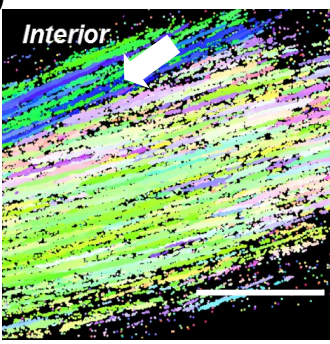

ii. Pole figure (Calcite)

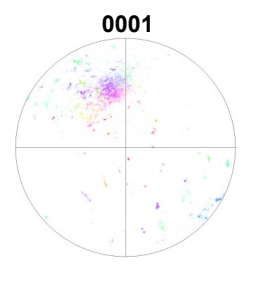

ii. Pole figure (Calcite)

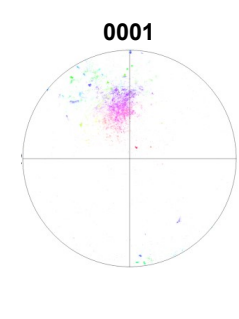

ii. Pole figure (Calcite)

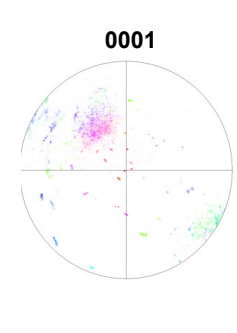

ii. Pole figure (Calcite)

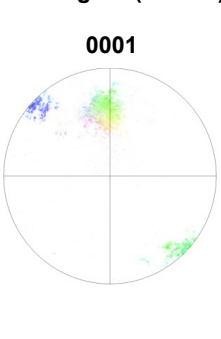

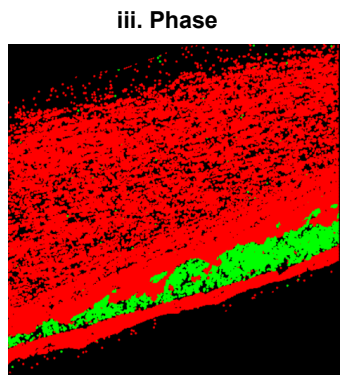

iii. Phase

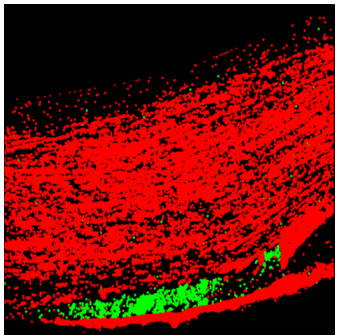

iii. Phase

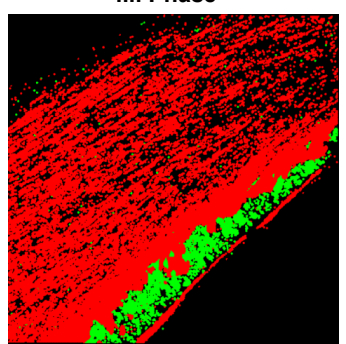

iii. Phase

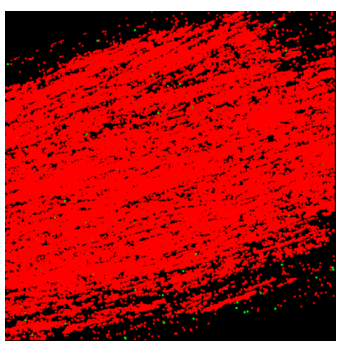

Colour key:

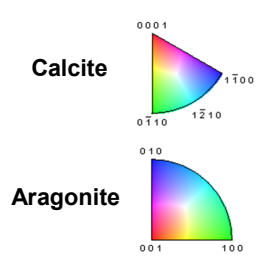

Figure 4. Electron back-scattered diffraction analyses of shells grown for 35 days at control $\mathrm{pH} 8.1$ (a), treatment $\mathrm{pH} 7.8$ (b), $\mathrm{pH} 7.5$ (c) and $\mathrm{pH} 7.2$ (d). Crystallographic orientation maps (left column) of calcite crystals in reference to the \{0001\} plane and aragonite crystals in reference to the $\{001\}$ plane. Crystallographic planes of calcite are colour-coded according to the normal crystallographic direction shown in the colour key (Perez-Huerta and Cusack, 2009). Pole figures for calcite (centre column) corresponding to the crystallographic orientation maps with the same colour key. The right column shows the phase maps of calcite exhibited in red and aragonite in green. The white arrow denotes a change in colour of 5 to 10 marginal foliated laminates. Scale bar $=45 \mu \mathrm{m}$.

(Fig. 4 left column) showed changes in crystallographic orientation from the control $(\mathrm{pH} 8.1)$ to low $\mathrm{pH}$ conditions $(\mathrm{pH} 7.8,7.5$ and 7.2) as represented by colour change corresponding to the colour key (Fitzer et al., 2014). The spread of data points in pole figures (Fig. 4 centre column) highlighted the variation in crystallographic orientation between the juvenile oysters under the low $\mathrm{pH}$ and the control conditions. Though the foliated layers of shells under decreased $\mathrm{pH}$ showed colour variations within a limited area $(\sim 5-10$ foliated laminas) close to the interior, the majority of calcite crystal units showed uniform orientation, the same as those in the control (Fig. 4 left and centre columns). It was confirmed by the pole figures that the preferred crystallographic orientation of foliated layers was identical, resulting in the extent of the variation in crystal orientation of $40^{\circ}$ regardless of $\mathrm{pH}$ treatments, corresponding to the colours in the orientation maps (Fig. 4 left column). But notably, there was an absence of aragonite in the shells formed under $\mathrm{pH} 7.2$ 

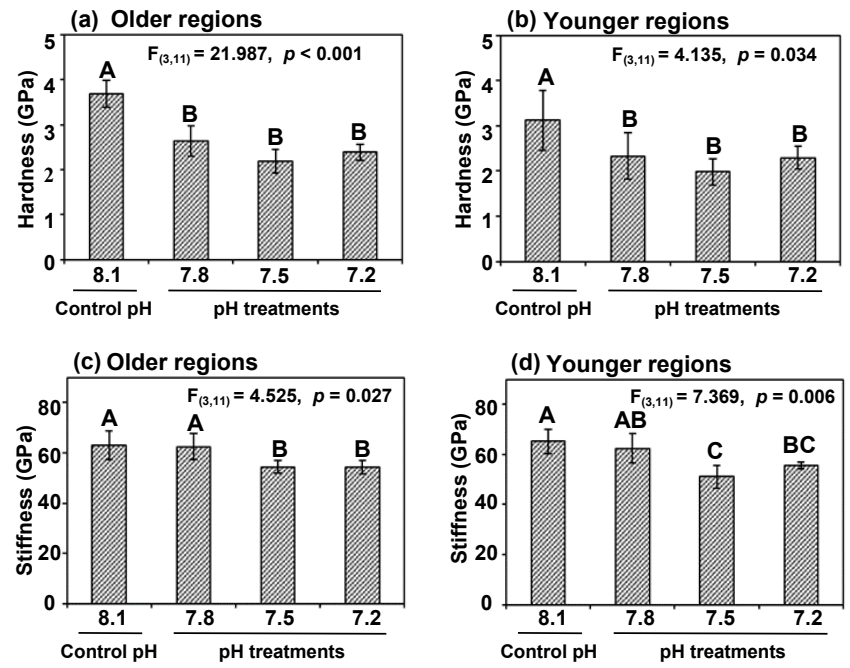

Figure 5. Shell mechanical properties in terms of hardness (a, b) and stiffness $(\mathbf{c}, \mathbf{d})$ with longer and shorter exposures in older hinge regions $(\mathbf{a}, \mathbf{c})$ and younger middle regions $(\mathbf{b}, \mathbf{d})$ in cross-sectional shell surfaces of Magallana angulata were compared. Data of mechanical properties are presented as mean \pm SD of three to four replicates $(n=3$ or 4$)$.

(Fig. 4 right column). Although the aragonitic crystals are not present in the most extreme treatment ( $\mathrm{pH} 7.2)$, the overall crystallographic orientation of the calcitic fraction did not change between treatments.

\subsection{Shell hardness and stiffness}

Shell hardness was significantly reduced as treatment $\mathrm{pH}$ decreased, relative to control (older region: $F_{(3,11)}=21.987$, $p<0.001$; younger region: $\left.F_{(3,11)}=4.135, p=0.034\right)$. Similarly, shells at $\mathrm{pH} 7.5$ and 7.2 had reduced stiffness compared to the controls (Fig. 5c, d) (older region: $F_{(3,11)}=$ $4.525, p=0.027$; younger region: $F_{(3,11)}=7.369, p=$ $0.006)$. The reduced mechanical features due to decreased $\mathrm{pH}$ were observed in both the older hinge regions and younger middle regions (Fig. 5).

\subsection{Shell density}

Three-dimensional shell density maps (Fig. 6a-d), the overall shell density and the relationship of shell density-volume ratio by micro-computed tomography (micro-CT) showed an overall decrease of shell density with decreasing $\mathrm{pH}$ (Fig. 6e) $\left(F_{(3,8)}=5.318, p=0.026\right)$. A similar decrease is visible in the linear regressions (volume ratio $(\%)=b \times$ density $\left.\left(\mathrm{g} \mathrm{cm}^{-3}\right)+a\right)$ in Fig. 6f. Volume ratios were decreased with the increased shell density in all $\mathrm{pH}$ treatments (ANCOVA; shell density, $\left.F_{(1,263)}=1253.14, p<0.001\right)$. There was an interaction between $\mathrm{pH}$ and shell density (ANCOVA; $\mathrm{pH} \times$ density, $\left.F_{(3,263)}=4.994, p=0.002\right)$, indicating that the effect of $\mathrm{pH}$ on the density-volume ratio relationship was different. The lower scaling of consumptions at $\mathrm{pH} 7.8$ (mean exponent -0.063), $\mathrm{pH} 7.5$ (mean exponent -0.065) and $\mathrm{pH} 7.2$ (mean exponent -0.062 ) versus the control $\mathrm{pH}$ level of 8.1 (mean exponent -0.052) indicates that the volume ratio of denser shell was reduced with decreased $\mathrm{pH}$ while the volume ratio of less dense shell was increased correspondingly (Fig. 6f). The three-dimensional shell density map (Fig. 6a-d) reinforces the effect of decreased $\mathrm{pH}$ on the density-volume ratio relationships. In the controls, shells were produced with denser minerals compared to shells in decreased pH (Fig. 6a). Shells at pH 7.8, pH 7.5 and $\mathrm{pH} 7.2$ had larger proportions of lower shell density regions or "pores" (Fig. 6b-d). These pores were observed in the three-dimensional density maps as density values below the detection threshold (Fig. 6a-d). Classifying the shell volumes into four density categories, i.e. $<0.5,0.5-1,1-$ 1.5 and $>1.5 \mathrm{~g} \mathrm{~cm}^{-3}$, showed that the proportions of high $\left(>1.5 \mathrm{~g} \mathrm{~cm}^{-3}\right)$ and low $\left(<0.5 \mathrm{~g} \mathrm{~cm}^{-3}\right)$ shell density areas were significantly different between $\mathrm{pH}$ treatments (Fig. 6ad). The volume ratios of high density areas were significantly reduced in each $\mathrm{pH}$ treatment $(\mathrm{pH} 7.8, \mathrm{pH} 7.5$ and $\mathrm{pH} 7.2)$ when compared to the controls $(\mathrm{pH} 8.1)\left(F_{(3,8)}=4.856\right.$, $p=0.033)$. Meanwhile, the volume ratios of low density areas $\left(<0.5 \mathrm{~g} \mathrm{~cm}^{-3}\right)$ significantly increased in each of the lower $\mathrm{pH}$ treatments $(\mathrm{pH} 7.8, \mathrm{pH} 7.5$ and $\mathrm{pH} 7.2)$ compared to the controls $\left(\mathrm{F}_{(3,8)}=6.945, p=0.013\right)$. There were no significant differences in the volume ratios of the middle densities $\left(0.5-1 \mathrm{~g} \mathrm{~cm}^{-3}: \chi_{(2)}^{2}=5.615, p=0.132 ; 1-1.5 \mathrm{~g} \mathrm{~cm}^{-3}\right.$ : $\left.F_{(3,8)}=3.713, p=0.061\right)$ among treatments (Fig. 6a-d).

\section{Discussion}

This study provided new compelling information of structure-property relationships in calcareous shells of commercially important oyster species at different spatial scales and under a variety of environmentally and climatically relevant OA scenarios (i.e. different levels of decreased $\mathrm{pH}$ via $p \mathrm{CO}_{2}$ increase). The revealed structural information and subsequent analysis of mechanical features in this study provided an important experimental basis for developing models to forecast the impact of ocean acidification on marine calcifying organisms. The rate of calcification of many marine organisms is expected to be significantly reduced in near-future oceans with a reduced pH of 7.8 due to OA (Ries, 2011; Bednarsek et al., 2012; Duquette et al., 2017; Chatzinikolaou et al., 2017). This study observed the same calcification trend in Magallana angulata because OA not only depletes carbonate ions necessary for $\mathrm{CaCO}_{3}$ mineralization, but it also metabolically weakens marine organisms through altered physiological processes, i.e. acidosis (Dupont and Portner, 2013). Importantly, this study provides strong evidence to support the argument that shells produced by oysters under OA suffer from dissolution with disorganized or impaired crystal orientation and microstructures, and reduced mechanical proper- 

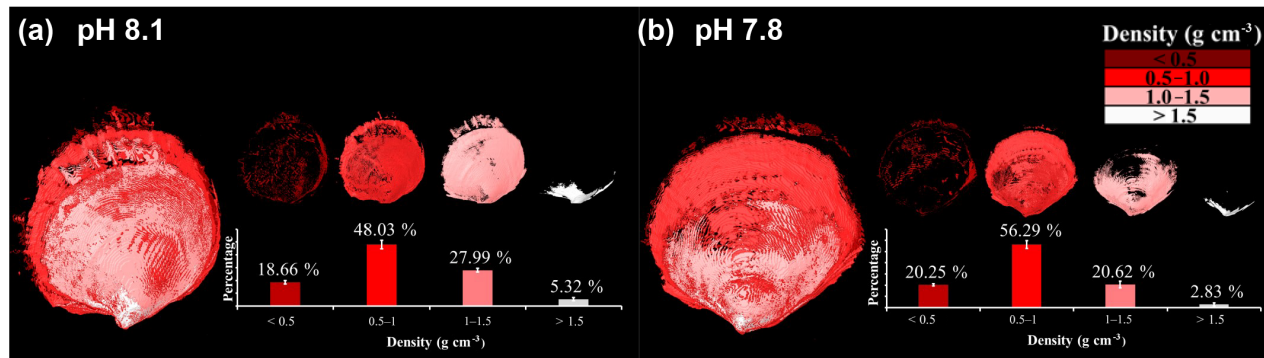

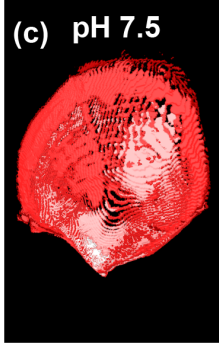

(e)

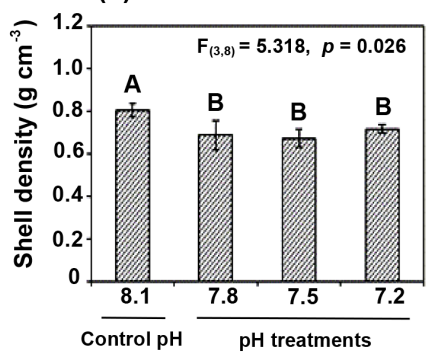

(d) $\mathrm{pH} 7.2$

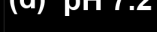

\section{(d) $\mathrm{pH} 7.2$}
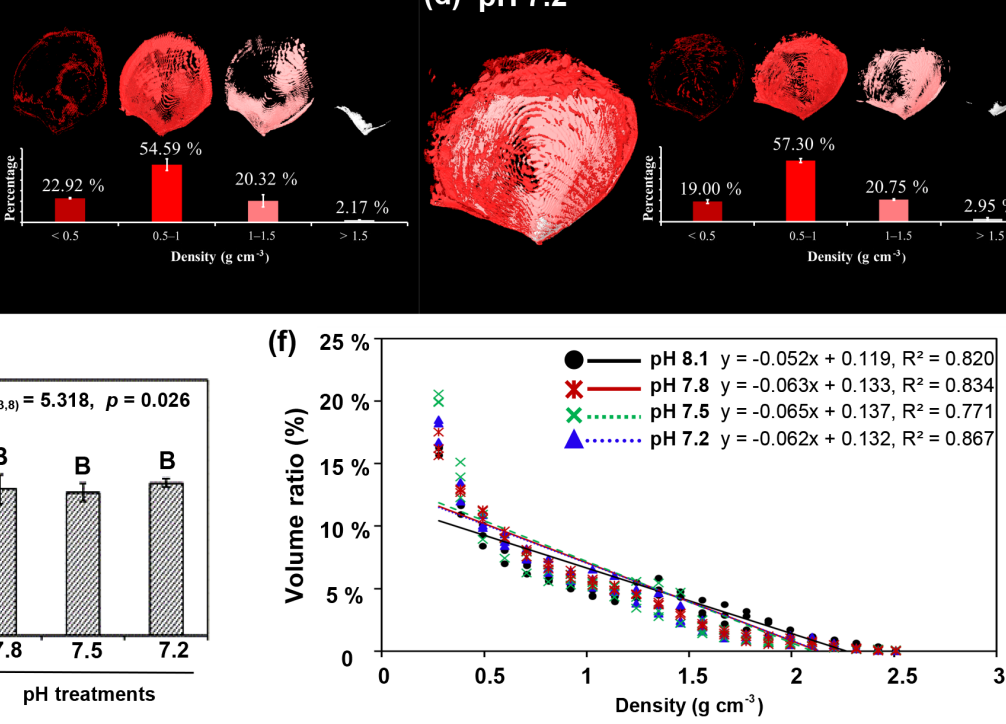

Figure 6. Effects of low $\mathrm{pH}$ on the shell density map (a-d), overall density (e), and shell density-volume ratio relationships (f) for the four experimental $\mathrm{pH}$ treatment groups were examined by micro-CT of shells of Magallana angulata. Three-dimensional reconstructions represent the density distribution of the shells produced in ambient or control $\mathrm{pH} 8.1$ (a), treatment $\mathrm{pH} 7.8$ (b), $\mathrm{pH} 7.5$ (c) and $\mathrm{pH} 7.2$ (d). The volume ratios of density categories of $<0.5,0.5-1.0,1.0-1.5$, and $>1.5 \mathrm{~g} \mathrm{~cm}^{-3}$ were quantified. (e) The overall density was presented as mean $\pm \mathrm{SD}$ of three replicates $(n=3)$. (f) shell density-volume ratio relationships for the four experimental $\mathrm{pH}$ treatment groups of $C$. angulata. Regression lines for the three low $\mathrm{pH}$ treatments closely overlap and are partly obscured.

ties. The possible mechanisms and consequences underlying such negative effects of decreased $\mathrm{pH}$ on mechanics of shell structure are discussed in the following sections.

\subsection{Effect of ocean acidification on shell mechanical features: a hierarchical analysis}

In any given biologically formed material, mechanical properties at the macroscale generally depend on the composition of material components and materials' microstructural features (Rodriguez-Navarro et al., 2002; Meng et al., 2018). In this study, oyster shell material is composed of two calcium carbonate polymorphs, calcite and aragonite. Oysters begin their life (larvae) with aragonite-based shells, and these are completely replaced by calcite in adult shells, though juvenile shells may retain a tiny portion of aragonite (Weiss et al., 2002). Calcite is relatively less soluble in seawater compared to aragonite regardless of environmental $\mathrm{pH}$. Calcite is a relatively less soluble form of $\mathrm{CaCO}_{3}$ in conditions with de- creased $\mathrm{pH}$ when compared to aragonite (Lippmann, 1973). This chemical feature of calcite may have made it feasible for the juvenile oysters to successfully mineralize and retain a laminated calcareous structure, even under undersaturated $\mathrm{CaCO}_{3}$ saturation levels, e.g. decreased pH 7.4 (Fig. 3).

Like the previously described oyster shell microstructure (Dauphin and Denis, 2000; MacDonald et al., 2010), the materials used in this study are composed of structurally organized layers. The bulk of the microstructure is characterized by foliated layers of crystal units organized in lamellae. In order to understand the modulating effect of environmental $\mathrm{pH}$ on the relationship between the shell structural and mechanical features, we have quantified the space or pore size between laminated layers within the folia. The decreased $\mathrm{pH}$ significantly increased size and quantity of the pores in the folia layer. The presence of such laminated folia with pores or gaps was an obvious consequence of decreased $\mathrm{pH}$. However, the larvae were still capable of producing a new foliated layer under these treatments whilst at undersaturation (at 
$\mathrm{pH}$ 7.2). Although the juvenile shells show signs of physical dissolution, the EBSD and porosity data suggest that the microstructure growth is impaired initially. This microstructural impairment was observed even under the near-future level of decreased $\mathrm{pH} 7.8$, where the porosity was increased 10-fold (Fig. 3r). On the other hand, the preferred orientation of crystal units within the folia layer showed no difference in all low $\mathrm{pH}$ treatments, with the $c$ axis of calcite units approximately perpendicular to the outer and inner shell surface. Thus, the significantly reduced hardness and stiffness of the foliated layer under decreased $\mathrm{pH}$ might be due to the impaired microstructure with significantly higher pore size and numbers.

Furthermore, we measured the impacts of decreased $\mathrm{pH}$ on whole shell density and thus on pores or gaps in foliated layers using micro-CT analysis. Notably, higher density shell volume reduces with decreasing $\mathrm{pH}$. This result supports our finding on the effect of decreased $\mathrm{pH}$ on microscale structure and mechanical features in the folia. Calcite shell materials are brittle in nature, like egg shells or ceramics; therefore their resistance to deformation (or breaking force) is largely dependent on the stiffness parameter of the shell (Lawn and Wilshaw, 1993). Here, we found that both hardness and stiffness of the folia layer reduce with decreasing $\mathrm{pH}$, which may have triggered shell fracture under simulated external attack. A folia layer with lower stiffness and hardness resulting from a porous laminated microstructure is expected to be highly vulnerable to predatory attack, even though the preferred orientation remains unaffected (Kemeny and Cook, 1986). In addition, the overall decrease of shell density detected by micro-CT analysis indicates the porous internal microstructure may occur throughout the juvenile shell. In other words, the juvenile oyster shell with impaired microstructural features is more prone to predator attack under the near-future level of decreased $\mathrm{pH}$ due to $\mathrm{OA}$ processes.

\subsection{Effect of ocean acidification on shell microstructure and crystallography}

The outermost prismatic layers of the older hinge and younger middle regions had completely disappeared when juvenile oysters were exposed to the extreme scenarios ( $\mathrm{pH}$ of 7.2 and calcite undersaturation $\Omega_{\text {cal }} \approx 0.66$ ) (Figs. $2 \mathrm{~h}$ and $3 n, p)$. Undersaturated waters, with regards to calcite $\left(\Omega_{c a l}<1\right)$, result in the dissolution of calcitic materials (Bednarsek et al., 2012; Lippmann, 1973). Similar impacts were observed in Argopecten irradians (pH 7.8 and $\mathrm{pH}$ 7.5) (Talmage and Gobler, 2010), Mercenaria mercenaria (pH 7.7) (Dickinson et al., 2013) and Saccostrea glomerata (pH 7.8 and pH 7.6) (Watson et al., 2009).

The juvenile oysters exposed to decreased $\mathrm{pH}$ exhibited a porous microstructure in foliated layers (Fig. 3). Firstly, this may be due to the decreased calcification rate resulted from the metabolic depression and/or energy shortage in the decreased $\mathrm{pH}$ conditions (Gobler and Talmage, 2014; Lannig et al., 2010). Secondly, it could be due to the dissolution of newly formed minerals of the inner surface in the lower $\mathrm{pH}$ conditions (Melzner et al., 2011). Marine invertebrates' calcification has highly controlled mechanisms and remains to be explored by further studies (Krause-Nehring et al., 2011). Animals are capable of actively increasing the site of calcification by pumping protons out of the calcification site, thereby enabling calcium carbonate precipitation (Ries et al., 2010; Toyofuku et al., 2017). Supersaturated calcite conditions of oysters were found restricted to the shell edge including the outer mantle and the first intracellular nucleation site (Mount et al., 2004). Undersaturated calcite conditions may be maintained elsewhere in contact with the inner shell surface (Addadi et al., 2006; Thomsen et al., 2010). Therefore, in low $\mathrm{pH}$ conditions due to $\mathrm{OA}$, these inner areas of newly formed minerals, which are precipitated as structural building blocks for the prismatic and foliated layers, may still be prone to dissolution. When the shell dissolution rate is faster than the mineralization rate, organisms tend to produce thinner and lighter (less dense) shells, resulting in an impaired shell microstructure. This may explain the multiple negative effects of reduced $\mathrm{pH}$ in our results, including porous and less dense foliated layers. Similarly, mussel shells grown in lower $\mathrm{pH}$ conditions ( $\mathrm{pH}$ 7.65) showed inner shell surface dissolution (Melzner et al., 2011) and an impaired shell microstructure (Hahn et al., 2012), which is consistent with the results in this study. The crystallography of marine shells is the other important proxy for environmental stressors (Milano et al., 2017). The crystallographic orientation maps of foliated layers showed a preferred crystallographic orientation with $\sim 40^{\circ}$ of variation regardless of $\mathrm{pH}$ treatments, which concurs with the results of field samples (Checa et al., 2018). Compared to calcite, aragonite represents a small fraction of the oyster shells and is more soluble under decreased $\mathrm{pH}$ conditions (Fitzer et al., 2014), which could explain the absence of aragonite in the older hinge regions at pH 7.2 (Fig. 4 right column) is observed in this study. A similar absence of aragonite was also reported in mussel shells in high $p \mathrm{CO}_{2}(1000 \mu \mathrm{atm})$ conditions (Fitzer et al., 2014). Nevertheless, aragonite dissolution may be very relevant for oyster shells during early life stages but not so much for adult shells. Therefore, it plays an insignificant role in shell mechanical properties of the calcite-predominant adult shells and thus the adult oyster survival.

\subsection{Ecological implications and conclusion}

Although previous studies showed that early larval life stages of several edible oyster species were relatively physiologically tolerant of near-future OA conditions (Dineshram et al., 2013; Ko et al., 2013, 2014; Thiyagarajan and Ko, 2012), this study shows that they are still vulnerable due to the effects decreased $\mathrm{pH}$ has on shell characteristics, like porosity, hardness and stiffness. A similar negative impact of OA on shell mechanical properties was reported in various marine calcifiers. For example, the pearl oyster, Pinctada fucata, 
produced a $25.9 \%$ weaker shell after exposure to seawater at pH 7.8 (Welladsen et al., 2010). Decreasing shell mechanical properties in decreased $\mathrm{pH}$ conditions were also observed in Mytilus californianus (Gaylord et al., 2011), which produced $20 \%$ weaker shells under pH 7.8, Mercenaria mercenaria (Dickinson et al., 2013; Ivanina et al., 2013), which produced approximately $60 \%$ softer shells under $\mathrm{pH} 7.77$ (16 salinity) and Hydroides elegans (Li et al., 2014), which produced $80 \%$ softer tubes under $\mathrm{pH}$ 7.8. However, the effects of increased carbon dioxide partial pressure $\left(p \mathrm{CO}_{2}\right)$ on shell mechanical properties are species-specific. Near-future conditions ( $\mathrm{pH}$ 7.8) did not affect shell hardness in the sea urchin Paracentrotus lividus (Collard et al., 2016) or in the barnacle Amphibalanus amphitrite (McDonald et al., 2009). Furthermore, juvenile oysters of $C$. gigas significantly increased their shell strength and size as a compensatory adaptive response to low $\mathrm{pH}$ conditions (i.e. $\mathrm{pH}$ 7.8) (Wright et al., 2014), and the blue mussel, Mytilus edulis, produced a stiffer and harder calcite layer under increased $p \mathrm{CO}_{2}$ conditions (i.e. pH 7.3) (Fitzer et al., 2015).

The long-term survival strategy of oysters with mechanically softer shells is yet to be studied. However, as shown in a recent study (Sanford et al., 2014), it appears that weaker shell structures will result in compromised defence abilities. Moreover, results from a recent study suggest that oysters with reduced and impaired calcification mechanisms have lower repair capabilities (Coleman et al., 2014). This hierarchical study revealed that the OA conditions may cause a deterioration of oyster shells and thus pose a serious threat to oyster survival and the health of coastal oyster reef structures in the near-future ocean. This biological effect of OA on shell structures and mechanical features should be incorporated in coastal oceanographic biophysical models to accurately project the survival of oysters in near-future coastal oceans which could be used for commercial shellfisheries to plan for sustainable growth under climate-change-induced acidification.

Data availability. All data related to the paper have been displayed in the text.

Author contributions. YM and TV conceived and designed the study. ZG and HY performed the nanoindentation test and contributed materials and analysis equipment. SCF and MC performed the EBSD analyses and contributed analysis equipment. YM and AU performed the $\mathrm{CO}_{2}$ propagation experiment. YM and CL performed the SEM imaging. KWKY contributed materials and analysis equipment for micro-CT scanning. YM analysed the data and drafted the manuscript. VBSC and TV contributed to the revisions.

Competing interests. The authors declare that they have no conflict of interest.
Acknowledgements. The authors would like to thank Shu Xiao and Yu Ziniu of the South China Sea Institute of Oceanology, Chinese Academy of Sciences (Guangzhou, China), for providing brood stocks for this work and for their assistance with the oyster larval culture. We acknowledge the University of Hong Kong EMU facility for helping with the SEM analysis. Thanks are given to Ying Yip Chui (University of Hong Kong, HKU) for sectioning and Tony Liu for helping with the micro-CT work. We thank Peter Chung of the Imaging Spectroscopy and Analysis Centre (ISAAC) of the School of Geographical \& Earth Sciences, University of Glasgow, for his support in the EBSD analyses.

This work was primarily supported by RGC-GRF grants to Vengatesen Thiyagarajan (no. 17303517 and no. 17304914). Maggie Cusack thanks the Scottish Universities Life Science Alliance (SULSA) and the Scottish Funding Council for funding the Hong Kong-Scotland Collaborative Research Partnership Award (2014_HK-Scot-0038). Susan C. Fitzer acknowledges the support of the University of Glasgow Principal's Early Career Mobility Scheme.

Edited by: Lennart de Nooijer

Reviewed by: two anonymous referees

\section{References}

Addadi, L., Joester, D., Nudelman, F., and Weiner, S.: Mollusk shell formation: a source of new concepts for understanding biomineralization processes, Chem. Eur. J., 12, 980-987, https://doi.org/10.1002/chem.200500980, 2006.

Barton, A., Hales, B., Waldbusser, G. G., Langdon, C., and Feely, R. A.: The Pacific oyster, Crassostrea gigas, shows negative correlation to naturally elevated carbon dioxide levels: Implications for near-term ocean acidification effects, Limnol. Oceanogr., 57, 698-710, https://doi.org/10.4319/lo.2012.57.3.0698, 2012.

Bednarsek, N., Tarling, G. A., Bakker, D. C. E., Fielding, S., Jones, E. M., Venables, H. J., Ward, P., Kuzirian, A., Leze, B., Feely, R. A., and Murphy, E. J.: Extensive dissolution of live pteropods in the Southern Ocean, Nat. Geosci., 5, 881-885, https://doi.org/10.1038/ngeo1635, 2012.

Beniash, E., Ivanina, A., Lieb, N. S., Kurochkin, I., and Sokolova, I. M.: Elevated level of carbon dioxide affects metabolism and shell formation in oysters Crassostrea virginica, Mar. Ecol. Prog. Ser., 419, 95-108, https://doi.org/10.3354/meps08841, 2010.

Celenk, C. and Celenk, P.: Bone density measurement using computed tomography, in: Computed Tomography - Clinical Applications, edited by: Saba, L., InTech, Rijeka, Croatia, 123-136, 2012.

Chan, V. B., Li, C., Lane, A. C., Wang, Y., Lu, X., Shih, K., Zhang, T., and Thiyagarajan, V.: $\mathrm{CO}_{2}$-driven ocean acidification alters and weakens integrity of the calcareous tubes produced by the serpulid tubeworm, Hydroides elegans, PloS ONE, 7, e42718, https://doi.org/10.1371/journal.pone.0042718, 2012.

Chatzinikolaou, E., Grigoriou, P., Keklikoglou, K., Faulwetter, S., and Papageorgiou, N.: The combined effects of reduced $\mathrm{pH}$ and elevated temperature on the shell density of two gastropod species measured using micro-CT imaging, ICES J. Mar. Sci., 74, 1135-1149, https://doi.org/10.1093/icesjms/fsw219, 2017. 
Checa, A. G., Harper, E. M., and González-Segura, A.: Structure and crystallography of foliated and chalk shell microstructures of the oyster Magallana: the same materials grown under different conditions, Sci. Rep., 8, 7507, https://doi.org/10.1038/s41598018-25923-6, 2018.

Coleman, D. W., Byrne, M., and Davis, A. R.: Molluscs on acid: gastropod shell repair and strength in acidifying oceans, Mar. Ecol. Prog. Ser., 509, 203-211, https://doi.org/10.3354/meps10887, 2014.

Collard, M., Rastrick, S. P. S., Calosi, P., Demolder, Y., Dille, J., Findlay, H. S., Hall-Spencer, J. M., Milazzo, M., Moulin, L., Widdicombe, S., Dehairs, F., and Dubois, P.: The impact of ocean acidification and warming on the skeletal mechanical properties of the sea urchin Paracentrotus lividus from laboratory and field observations, ICES J. Mar. Sci., 73, 727-738, https://doi.org/10.1093/icesjms/fsv018, 2016.

Dauphin, Y. and Denis, A.: Structure and composition of the aragonitic crossed lamellar layers in six species of Bivalvia and Gastropoda, Comp. Biochem. Physiol. A, 126, 367-377, https://doi.org/10.1016/S1095-6433(00)00213-0, 2000.

De Bodt, C., Van Oostende, N., Harlay, J., Sabbe, K., and Chou, L.: Individual and interacting effects of $p \mathrm{CO}_{2}$ and temperature on Emiliania huxleyi calcification: study of the calcite production, the coccolith morphology and the coccosphere size, Biogeosciences, 7, 1401-1412, https://doi.org/10.5194/bg-7-14012010, 2010.

Dickinson, G. H., Ivanina, A. V., Matoo, O. B., Portner, H. O., Lannig, G., Bock, C., Beniash, E., and Sokolova, I. M.: Interactive effects of salinity and elevated $\mathrm{CO}_{2}$ levels on juvenile eastern oysters, Crassostrea virginica, J. Exp. Biol., 215, 29-43, https://doi.org/10.1242/jeb.061481, 2012.

Dickinson, G. H., Matoo, O. B., Tourek, R. T., Sokolova, I. M., and Beniash, E.: Environmental salinity modulates the effects of elevated $\mathrm{CO}_{2}$ levels on juvenile hard-shell clams, Mercenaria mercenaria, J. Exp. Biol., 216, 2607-2618, https://doi.org/10.1242/jeb.082909, 2013.

Dickson, A. G. and Millero, F. J.: A comparison of the equilibrium constants for the dissociation of carbonic acid in seawater media, Deep Sea Res. (I Oceanogr. Res. Pap.), 34, 1733-1743, https://doi.org/10.1016/0198-0149(87)90021-5, 1987.

Dineshram, R., Thiyagarajan, V., Lane, A., Yu, Z., Xiao, S., and Leung, P. T. Y.: Elevated $\mathrm{CO}_{2}$ alters larval proteome and its phosphorylation status in the commercial oyster, Crassostrea hongkongensis, Mar. Biol., 160, 2189-2205, https://doi.org/10.1007/s00227-013-2176-x, 2013.

Doerner, M. F. and Nix, W. D.: A method for interpreting the data from depth-sensing indentation instruments, J. Mater. Res., 1, 601-609, https://doi.org/10.1557/JMR.1986.0601, 1986.

Duarte, C. M., Hendriks, I. E., Moore, T. S., Olsen, Y. S., Steckbauer, A., Ramajo, L., Carstensen, J., Trotter, J. A., and McCulloch, M.: Is ocean acidification an ppen-ocean syndrome? Understanding anthropogenic impacts on seawater $\mathrm{pH}$, Estuar. Coast., 36, 221-236, https://doi.org/10.1007/s12237-013-9594-3, 2013.

Dupont, S. and Portner, H.: Marine science: Get ready for ocean acidification, Nature, 498, 429-429, https://doi.org/10.1038/498429a, 2013.

Duquette, A., McClintock, J. B., Amsler, C. D., Pérez-Huerta, A., Milazzo, M., and Hall-Spencer, J. M.: Effects of ocean acidification on the shells of four Mediterranean gastropod species near a $\mathrm{CO}_{2}$ seep, Mar. Pollut. Bull., 124, 917-928, https://doi.org/10.1016/j.marpolbul.2017.08.007, 2017.

Feely, R. A., Orr, J., Fabry, V. J., Kleypas, J. A., Sabine, C. L., and Langdon, C.: Present and future changes in seawater chemistry due to ocean acidification., Geophys. Monogr. Ser., 183, 175188, https://doi.org/10.1029/2005GM000337, 2009.

Fitzer, S. C., Cusack, M., Phoenix, V. R., and Kamenos, N. A.: Ocean acidification reduces the crystallographic control in juvenile mussel shells, J. Struct. Biol., 188, 39-45, https://doi.org/10.1016/j.jsb.2014.08.007, 2014.

Fitzer, S. C., Zhu, W., Tanner, K. E., Phoenix, V. R., Kamenos, N. A., and Cusack, M.: Ocean acidification alters the material properties of Mytilus edulis shells, J. R. Soc. Lond. Interface, 12, 20141227, https://doi.org/10.1098/rsif.2014.1227, 2015.

Galtsoff, P. S.: The American oyster, Crassostrea virginica Gmelin, Fish. Bull., 64, 1-480, 1964.

Gaylord, B., Hill, T. M., Sanford, E., Lenz, E. A., Jacobs, L. A., Sato, K. N., Russell, A. D., and Hettinger, A.: Functional impacts of ocean acidification in an ecologically critical foundation species, J. Exp. Biol., 214, 2586-2594, https://doi.org/10.1242/jeb.055939, 2011.

Gobler, C. J. and Talmage, S. C.: Physiological response and resilience of early life-stage Eastern oysters (Crassostrea virginica) to past, present and future ocean acidification, Conserv. Physiol., 2, cou004, https://doi.org/10.1093/conphys/cou004, 2014.

Hahn, S., Rodolfo-Metalpa, R., Griesshaber, E., Schmahl, W. W., Buhl, D., Hall-Spencer, J. M., Baggini, C., Fehr, K. T., and Immenhauser, A.: Marine bivalve shell geochemistry and ultrastructure from modern low $\mathrm{pH}$ environments: environmental effect versus experimental bias, Biogeosciences, 9, 1897-1914, https://doi.org/10.5194/bg-9-1897-2012, 2012.

Han, Y. H., Li, H., Wong, T. Y., and Bradt, R. C.: Knoop Microhardness Anisotropy of Single-Crystal Aragonite, J. Am. Ceram. Soc., 74, 3129-3132, https://doi.org/10.1111/j.11512916.1991.tb04311.x, 1991.

Ivanina, A. V., Dickinson, G. H., Matoo, O. B., Bagwe, R., Dickinson, A., Beniash, E., and Sokolova, I. M.: Interactive effects of elevated temperature and $\mathrm{CO}_{2}$ levels on energy metabolism and biomineralization of marine bivalves Crassostrea virginica and Mercenaria mercenaria, Comp. Biochem. Phys. A, 166, 101111, https://doi.org/10.1016/j.cbpa.2013.05.016, 2013.

Kemeny, J. and Cook, N. G. W.: Effective moduli, non-linear deformation and strength of a cracked elastic solid, Int. J. Rock Mech. Min., 23, 107-118, https://doi.org/10.1016/01489062(86)90337-2, 1986.

Ko, G. W. K., Dineshram, R., Campanati, C., Chan, V. B. S., Havenhand, J., and Thiyagarajan, V.: Interactive effects of ocean acidification, elevated temperature, and reduced salinity on early-life stages of the Pacific oyster, Environ. Sci. Technol., 48, 1007910088, https://doi.org/10.1021/es501611u, 2014.

Ko, G. W. K., Chan, B. S. V., Dineshram, R., Choi, K. S. D., Li, J. A., Yu, Z., and Thiyagarajan, V.: Larval and post-Larval stages of Pacific oyster (Crassostrea gigas) are resistant to elevated $\mathrm{CO}_{2}$, PloS ONE, 8, e64147, https://doi.org/10.1371/journal.pone.0064147, 2013.

Krause-Nehring, J., Klügel, A., Nehrke, G., Brellochs, B., and Brey, T.: Impact of sample pretreatment on the measured element concentrations in the bivalve Arctica islandica, Geochem. Geophy. 
Geosys., 12, Q07015, https://doi.org/10.1029/2011GC003630, 2011.

Lannig, G., Eilers, S., Portner, H. O., Sokolova, I. M., and Bock, C.: Impact of ocean acidification on energy metabolism of oyster, Crassostrea gigas-changes in metabolic pathways and thermal response, Mar. Drugs, 8, 2318-2339, https://doi.org/10.3390/md8082318, 2010.

Lawn, B. and Wilshaw, T. R.: Fracture of brittle solids, Cambridge University Press, Cambridge, 143 pp., 1993.

Lee, S. W., Kim, Y. M., Kim, R. H., and Choi, C. S.: Nano-structured biogenic calcite: A thermal and chemical approach to folia in oyster shell, Micron, 39, 380-386, https://doi.org/10.1016/j.micron.2007.03.006, 2008.

Lee, S. W., Jang, Y. N., Ryu, K. W., Chae, S. C., Lee, Y. H., and Jeon, C. W.: Mechanical characteristics and morphological effect of complex crossed structure in biomaterials: fracture mechanics and microstructure of chalky layer in oyster shell, Micron, 42, 60-70, https://doi.org/10.1016/j.micron.2010.08.001, 2011.

Li, C., Chan, V. B. S., He, C., Meng, Y., Yao, H., Shih, K., and Thiyagarajan, V.: Weakening mechanisms of the serpulid tube in a high- $\mathrm{CO}_{2}$ world, Environ. Sci. Technol., 48, 14158-14167, https://doi.org/10.1021/es501638h, 2014.

Lippmann, F.: Sedimentary carbonate minerals, Springer Verlag, Berlin, 1973.

MacDonald, J., Freer, A., and Cusack, M.: Alignment of crystallographic $c$-axis throughout the four distinct microstructural layers of the oyster Crassostrea gigas, Cryst. Growth Des., 10, 1243 1246, https://doi.org/10.1021/cg901263p, 2010.

McDonald, M. R., McClintock, J. B., Amsler, C. D., Rittschof, D., Angus, R. A., Orihuela, B., and Lutostanski, K.: Effects of ocean acidification over the life history of the barnacle Amphibalanus amphitrite, Mar. Ecol. Prog. Ser., 385, 179-187, https://doi.org/10.3354/meps08099, 2009.

Medaković, D., Popović, S., Gržeta, B., Plazonić, M., and HrsBrenko, M.: X-ray diffraction study of calcification processes in embryos and larvae of the brooding oyster Ostrea edulis, Mar. Biol., 129, 615-623, https://doi.org/10.1007/s002270050204, 1997.

Mehrbach, C., Culberson, C. H., Hawley, J. E., and Pytkowicx, R. M.: Measurement of the apparent dissociation constants of carbonic acid in seawater at atmospheric pressure, Limnol. Oceanogr., 18, 897-907, https://doi.org/10.4319/lo.1973.18.6.0897, 1973.

Melzner, F., Stange, P., Trübenbach, K., Thomsen, J., Casties, I., Panknin, U., Gorb, S. N., and Gutowska, M. A.: Food supply and seawater $p \mathrm{CO}_{2}$ impact calcification and internal shell dissolution in the blue mussel Mytilus edulis, PloS ONE, 6, e24223, https://doi.org/10.1371/journal.pone.0024223, 2011.

Meng, Y., Fitzer, S. C., Chung, P., Li, C., Thiyagarajan, V., and Cusack, M.: Crystallographic Interdigitation in Oyster Shell Folia Enhances Material Strength, Cryst. Growth Des., 18, 3753-3761, https://doi.org/10.1021/acs.cgd.7b01481, 2018.

Milano, S., Schöne, B. R., Wang, S., and Müller, W. E.: Impact of high $p \mathrm{CO}_{2}$ on shell structure of the bivalve Cerastoderma edule, Mar. Environ. Res., 119, 144-155, doi.org/10.1016/j.marenvres.2016.06.002, 2016.

Milano, S., Nehrke, G., Wanamaker Jr., A. D., Ballesta-Artero, I., Brey, T., and Schöne, B. R.: The effects of environment on Arc- tica islandica shell formation and architecture, Biogeosciences, 14, 1577-1591, https://doi.org/10.5194/bg-14-1577-2017, 2017.

Mount, A. S., Wheeler, A. P., Paradkar, R. P., and Snider, D.: Hemocyte-mediated shell mineralization in the eastern oyster, Science, 304, 297-300, https://doi.org/10.1126/science.1090506, 2004.

Newell, R. I. E., Kennedy, V. S., and Shaw, K. S.: Comparative vulnerability to predators, and induced defense responses, of eastern oysters Crassostrea virginica and non-native Crassostrea ariakensis oysters in Chesapeake Bay, Mar. Biol., 152, 449-460, https://doi.org/10.1007/s00227-007-0706-0, 2007.

Oliver, W. C. and Pharr, G. M.: An improved technique for determining hardness and elastic modulus using load and displacement sensing indentation experiments, J. Mater. Res., 7, 15641583, https://doi.org/10.1557/JMR.1992.1564, 1992.

Perez-Huerta, A., Cusack, M., Zhu, W., England, J., and Hughes, J.: Material properties of brachiopod shell ultrastructure by nanoindentation, J. R. Soc. Lond. Interface, 4, 33-39, https://doi.org/10.1098/rsif.2006.0150, 2007.

Perez-Huerta, A. and Cusack, M.: Optimizing electron backscatter diffraction of carbonate biominerals-resin type and carbon coating, Microsc. Microanal., 15, 197-203, https://doi.org/10.1017/S1431927609090370, 2009.

Pierrot, D., Lewis, E., and Wallace, D.: MS Excel program developed for $\mathrm{CO}_{2}$ system calculations, ORNL/CDIAC-105a. Carbon Dioxide Information Analysis Center, Oak Ridge National Laboratory, US Department of Energy, Oak Ridge, Tennessee, 2006.

Ries, J. B.: Skeletal mineralogy in a high- $\mathrm{CO}_{2}$ world, J. Exp. Mar. Bio. Ecol., 403, 54-64, https://doi.org/10.1016/j.jembe.2011.04.006, 2011.

Ries, J. B., Cohen, A. L., and McCorkle, D. C.: A nonlinear calcification response to $\mathrm{CO}_{2}$-induced ocean acidification by the coral Oculina arbuscula, Coral Reefs, 29, 661-674, https://doi.org/10.1007/s00338-010-0632-3, 2010.

Rodriguez-Navarro, A., Kalin, O., Nys, Y., and Garcia-Ruiz, J. M.: Influence of the microstructure on the shell strength of eggs laid by hens of different ages, Br. Poult. Sci., 43, 395-403, https://doi.org/10.1080/00071660120103675, 2002.

Salvi, D. and Mariottini, P.: Molecular taxonomy in 2D: a novel ITS2 rRNA sequence-structure approach guides the description of the oysters' subfamily Saccostreinae and the genus Magallana (Bivalvia: Ostreidae), Zool. J. Linn. Soc., 179, 263-276, https://doi.org/10.1111/zoj.12455, 2017.

Sanford, E., Gaylord, B., Hettinger, A., Lenz, E. A., Meyer, K., and Hill, T. M.: Ocean acidification increases the vulnerability of native oysters to predation by invasive snails, P. R. Soc. Lond. B, 281, 20132681, https://doi.org/10.1098/rspb.2013.2681, 2014.

Talmage, S. C. and Gobler, C. J.: Effects of past, present, and future ocean carbon dioxide concentrations on the growth and survival of larval shellfish, P. Natl. Acad. Sci. USA, 107, 17246-17251, https://doi.org/10.1073/pnas.0913804107, 2010.

$\mathrm{R}$ Core Team: R: a language and environment for statistical computing. R Development Core Team, Vienna, 2013.

Teniswood, C. M. H., Roberts, D., Howard, W. R., Bray, S. G., and Bradby, J. E.: Microstructural shell strength of the Subantarctic pteropod Limacina helicina antarctica, Polar Biol., 39, 1643 1652, https://doi.org/10.1007/s00300-016-1888-z, 2016.

Thiyagarajan, V. and Ko, G. W. K.: Larval growth response of the Portuguese oyster (Crassostrea angulata) to multi- 
ple climate change stressors, Aquaculture, 370-371, 90-95, https://doi.org/10.1016/j.aquaculture.2012.09.025, 2012.

Thomsen, J., Gutowska, M. A., Saphörster, J., Heinemann, A., Trübenbach, K., Fietzke, J., Hiebenthal, C., Eisenhauer, A., Körtzinger, A., Wahl, M., and Melzner, F.: Calcifying invertebrates succeed in a naturally $\mathrm{CO}_{2}$-rich coastal habitat but are threatened by high levels of future acidification, Biogeosciences, 7, 3879-3891, https://doi.org/10.5194/bg-7-3879-2010, 2010.

Thomsen, J., Haynert, K., Wegner, K. M., and Melzner, F.: Impact of seawater carbonate chemistry on the calcification of marine bivalves, Biogeosciences, 12, 4209-4220, https://doi.org/10.5194/bg-12-4209-2015, 2015.

Toyofuku, T., Matsuo, M. Y., de Nooijer, L. J., Nagai, Y., Kawada, S., Fujita, K., Reichart, G.-J., Nomaki, H., Tsuchiya, M., Sakaguchi, H., and Kitazato, H.: Proton pumping accompanies calcification in foraminifera, Nat. Commun., 8, 14145, https://doi.org/10.1038/ncomms14145, 2017.

Watson, S.-A., Southgate, P. C., Tyler, P. A., and Peck, L. S.: Early larval development of the Sydney rock oyster Saccostrea glomerata under near-future predictions of $\mathrm{CO}_{2-}$ driven ocean acidification, J. Shellfish Res., 28, 431-437, https://doi.org/10.2983/035.028.0302, 2009.
Weiner, S., and Addadi, L.: Design strategies in mineralized biological materials, J. Mater. Chem., 7, 689-702, https://doi.org/10.1039/A604512J, 1997.

Weiss, I. M., Tuross, N., Addadi, L., and Weiner, S.: Mollusc larval shell formation: amorphous calcium carbonate is a precursor phase for aragonite, J. Exp. Biol., 293, 478-491, https://doi.org/10.1002/jez.90004, 2002.

Welladsen, H. M., Southgate, P. C., and Heimann, K.: The effects of exposure to near-future levels of ocean acidification on shell characteristics of Pinctada fucata (Bivalvia: Pteriidae), Molluscan Res., 30, 125-130, 2010.

Wright, J. M., Parker, L. M., O’Connor, W. A., Williams, M., Kube, P., and Ross, P. M.: Populations of Pacific oysters Crassostrea gigas respond variably to elevated $\mathrm{CO}_{2}$ and predation by Morula marginalba, Biol. Bull., 226, 269-281, https://doi.org/10.1086/BBLv226n3p269, 2014. 